\title{
Isquemia renal aguda - causa rara de lumbalgia
}

\author{
L. Xambre*, M. Cerqueira*, V. Silva*, M. Almeida*, R. Prisco*, F. Carreira*, A. Paiva** \\ *Servicio de Urología. Hospital Pedro Hispano. \\ **Servicio de Nefrología. Instituto Português de Oncologia. Porto. Portugal.
}

Actas Urol Esp 2005; 29 (3): 322-331

\begin{abstract}
RESUMEN
ISQUEMIA RENAL AGUDA - CAUSA RARA DE LUMBALGIA

La oclusión aguda de la arteria renal raramente se encuentra en la práctica clínica diaria. Su rareza y presentación clínica inespecífica son responsables por diagnóstico tardío o incluso por errores de diagnóstico, con síntomas que frecuentemente son atribuidos a otras entidades más comunes.

No existe consenso en cuanto al abordaje terapéutico. Se describen modalidades de tratamiento múltiples en la literatura disponible. La terapia anticoagulante y medidas de apoyo son defendidas por algunos mientras otros recomiendan alternativas más invasivas, existiendo incluso autores que recomiendan cirugía abierta.

Los autores presentan dos casos adicionales de isquemia renal aguda embolica. También es presentada una revisión exhaustiva de la literatura englobando aspectos etiológicos, clínicos, diagnósticos y aspectos terapéuticos.

Palabras clave: Embolia renal. Infarto renal.
\end{abstract}

\section{ABSTRACT}

\section{ACUTE RENAL ISCHEMIA - UNUSUAL CAUSE OF LUMBAR PAIN}

Acute renal artery occlusion is rarely found in daily clinical practice. Its rarity and inespecific clinical presentation are responsible for late diagnosis or diagnostic errors, with symptoms frequently being erroneously attributed to other more common entities.

There is no consensus in what concerns therapeutic options. Multiple treatment modalities are described in the available literature. Some defend anticoagulant therapy and support measures only while others recommend other more invasive alternatives reaching even open surgery.

The authors present two additional case reports of acute embolic renal ischemia. A thorough literature review is also presented comprehending etiological, clinic, diagnostic and therapeutic aspects. Keywords: Renal embolism. Renal infarction.

$\mathrm{L}^{\mathrm{a}}$ a embolia de la arteria renal constituye la causa más importante de infarto renal, siendo origen frecuente de hipertensión o de fracaso renal. Aunque es rara como evento diagnóstico, diversos estudios, basados en datos procedentes de autopsias, sugieren que su ocurrencia es más frecuente de lo que se podría pensar. Su diagnóstico, sin embargo, requiere una elevada sospecha clínica para poder realizar las pruebas diagnósticas apropiadas.
Virtualmente todas las situaciones de este tipo referenciadas en la bibliografía, corresponden a casos aislados o a series pequeñas, a menudo con críticas basadas en la heterogeneidad de su etiología. Esta heterogeneidad motiva la falta de respuesta a diversas cuestiones, particularmente aquellas relacionadas con la historia natural, definición de algoritmos de tratamiento de consenso y resultados proporcionados por las diferentes opciones terapéuticas. 
En este trabajo describimos dos casos clínicos y presentamos una revisión de los aspectos fisiopatológicos y las opciones disponibles de tratamiento.

\section{CASOS CLÍNICOS}

\section{Caso 1}

Enferma de 50 años, con antecedentes de estenosis mitral secundaria a fiebre reumática, medicada con anticoagulantes orales por fibrilación auricular, levotiroxina, y propanolol. Con antecedentes de hipotiroidismo iatrogénico (tiroidectomía total por carcinoma papilar). Ingresa en urgencias por persistencia del cuadro clínico, caracterizado por intenso dolor, súbito y continuo, en fosa iliaca izquierda sin irradiación o posición antiálgica, acompañado de náuseas y vómitos, con aproximadamente 11 horas de evolución. Sin otras quejas. Sin hematúria macroscópica.

Al examen físico, la paciente estaba conscien-

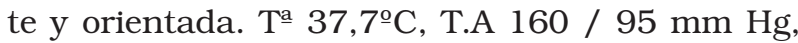
pulso arrítmico, $\pm 100 \mathrm{bpm}$. Auscultación cardíaca que indica soplo diastólico II /VI localizado en los focos de la base. Abdomen blando, doloroso a la palpación profunda en fosa ilíaca izquierda, sin señales de irritación peritoneal. Auscultación abdominal con disminución de los ruidos intestinales, timbre normal. Miembros superiores e inferiores sin déficit de perfusión. Examen neurológico general sin alteraciones.

El estudio analítico reveló una $\mathrm{Hb}$ de 10,9 g/dL, Leuc $15.800 / \mu \mathrm{L}$, Neut $85 \%$, Creat $1,2 \mathrm{mg} / \mathrm{dL}$, TGO y TGP de aproximadamente 1,5 veces por encima de los valores de referencia, LDH 2.100 UI/L, INR 1,8. El análisis de orina reveló hematuria y proteinuria de 0,3 g/L. El ECG confirma ritmo de fibrilación auricular, con respuesta ventricular controlada $( \pm 90 \mathrm{bpm})$.

Se informa clinicamente como diverticulitis. El TAC de abdomen y pelvis reveló ausencia de alteraciones intra-abdominales (Fig. 1A), con la excepción de la ausencia de captación de contraste por parte del riñón izquierdo, que presentó dimensiones y morfología normales. El riñón derecho no presentó alteraciones.

Sometida a arteriografía renal selectiva (Fig. 1B) se observa una imagen de "stop" a nivel del lecho común de la arteria renal izquierda, con
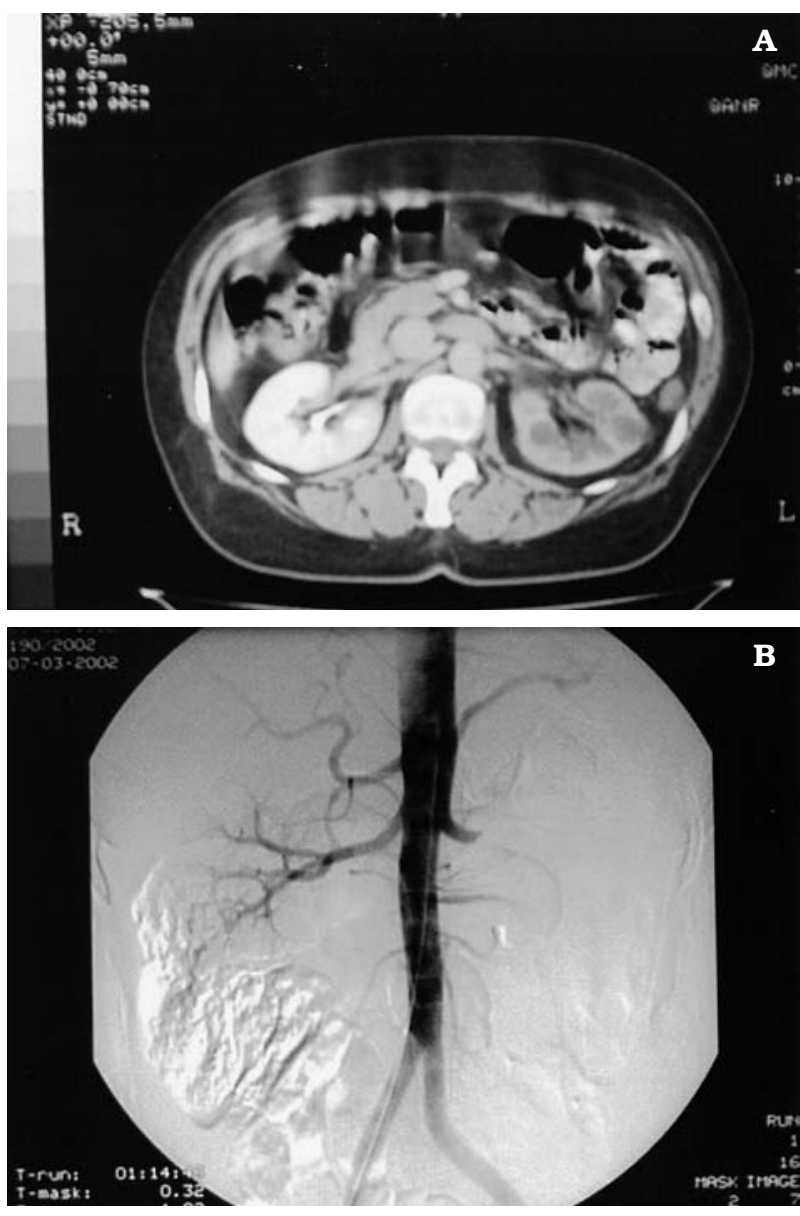

FIGURA 1: Caso 1 - Estudios de imagen

A) TAC de contraste - ausencia de captación de contraste por el riñón izquierdo.

B) Arteriografia - imagen de "stop" a nivel de la rama común de la arteria renal izquierda.

oclusión total del mismo. Ante la imposibilidad técnica de lograr una trombolisis intra-arterial "in-situ", se realizó una embolectomía quirúrgica, por medio de una arteriotomía y extracción del émbolo con catéter de Fogarty. La exploración quirúrgica confirmó la presencia del émbolo impactado en la arteria renal principal izquierda. Después de la embolectomía, cierre de la arteriotomía y declampage de la arteria, se comprobó una reperfusión inmediata del riñón. En el periodo post-operatorio no hubo complicaciones. Se ajustaron los niveles de anticoagulantes orales.

Después de 12 meses de seguimiento, la paciente sigue asintomática. No se han detectado episodios adicionales de embolia, ni desarrollo de hipertensión arterial. En el último control analíti- 
co, la creatinina fue $1,1 \mathrm{mg} / \mathrm{dL}$. Sin embargo, la cintigrafía renal demuestra marcada hipofunción del riñón izquierdo - función renal diferencial $22 \%$.

\section{Caso 2}

Varón de 43 años que ingresa en urgencias debido a un súbito dolor lumbar izquierdo, continuo e incapacitante, sin posición antiálgica o factores agravantes, sin irradiación, con aproximadamente 23 horas de evolución. Sin náuseas o vómitos, sin hematuria macroscópica o molestias en el tracto urinario inferior. Ausencia de dolor precordial. Hipertensión controlada con verapamilo. Refiere un episodio, interpretado como accidente isquémico transitorio, aproximadamente ocho semanas antes (no confirmado). Sin antecedentes de arritmia cardíaca o valvulopatía. Sin otros episodios tromboembólicos anteriores. Sin antecedentes conocidos de litiasis urinaria. Sin molestias osteoarticulares o respiratorias. Niega abuso de cocaína. Niega antecedentes de hepatitis B o C. Medicado con 160 mg/día de verapamilo.

En el examen físico se presentó diaforético, TA 150 / $110 \mathrm{mmHg}, 80$ pulsaciones por minuto, rítmicas y anchas. $\mathrm{T}^{\mathrm{a}}$ de $37,8^{\circ} \mathrm{C}$. Abdomen doloroso a la palpación profunda en fosa ilíaca y flanco izquierdos, con defensa, sin señales de irritación peritoneal. RHA disminuido. Sin soplos abdominales. Murphy renal bilateral negativo. Existencia de pulsos arteriales simétricos. Sin déficit de perfusión en extremidades. Examen neurológico general sin alteraciones.

La ecografía renal no evidenció anomalías, especialmente dilatación del tracto urinario. Datos analíticos: $\mathrm{Hb} 15,6 \mathrm{~g} / \mathrm{dL}$, Leuc 13.800/ $\mathrm{LL}$, Neut 76,1\%, Creat $1,4 \mathrm{mg} / \mathrm{dL}$, TGO $104 \mathrm{UI} / \mathrm{L}$, TGP 74 UI/L, LDH 1.890 UI/L. Los parámetros de coagulación no presentaron alteraciones. El ECG muestra ritmo sinusal, sin alteraciones compatibles con isquemia miocárdica aguda. Se solicitó un TAC abdominal y pélvico (Fig. 2A) que demostró la presencia de áreas múltiples sin captación de contraste en el riñón izquierdo, sin alteraciones morfo-estructurales del mismo, compatible con áreas multifocales de isquemia, con distribución multisegmentar probablemente de etiología embolica. Sin dilatación aórtica o aneuris- ma de arteria renal. Sin alteraciones intra-peritoneales. Teniendo en cuenta la distribución multisegmentar del proceso isquémico y la duración de las molestias, decidimos que no existía indicación para maniobras invasivas. El enfermo se sometió a hipo-coagulación sistémica con heparina, en un intento de evitar futuros episodios embólicos y analgesia apropiada.

Después fue sometido a múltiples exploraciones, en un intento de identificar un foco embólico y el proceso etiológico. La realización de una ecocardiografía eliminó patología del aparato valvular cardiaco o la existencia de vegetaciones valvulares. Ausencia de áreas de discinesia miocárdica. La arteriografía mostró un déficit de perfusión del polo inferior del riñón izquierdo con otras múlti-
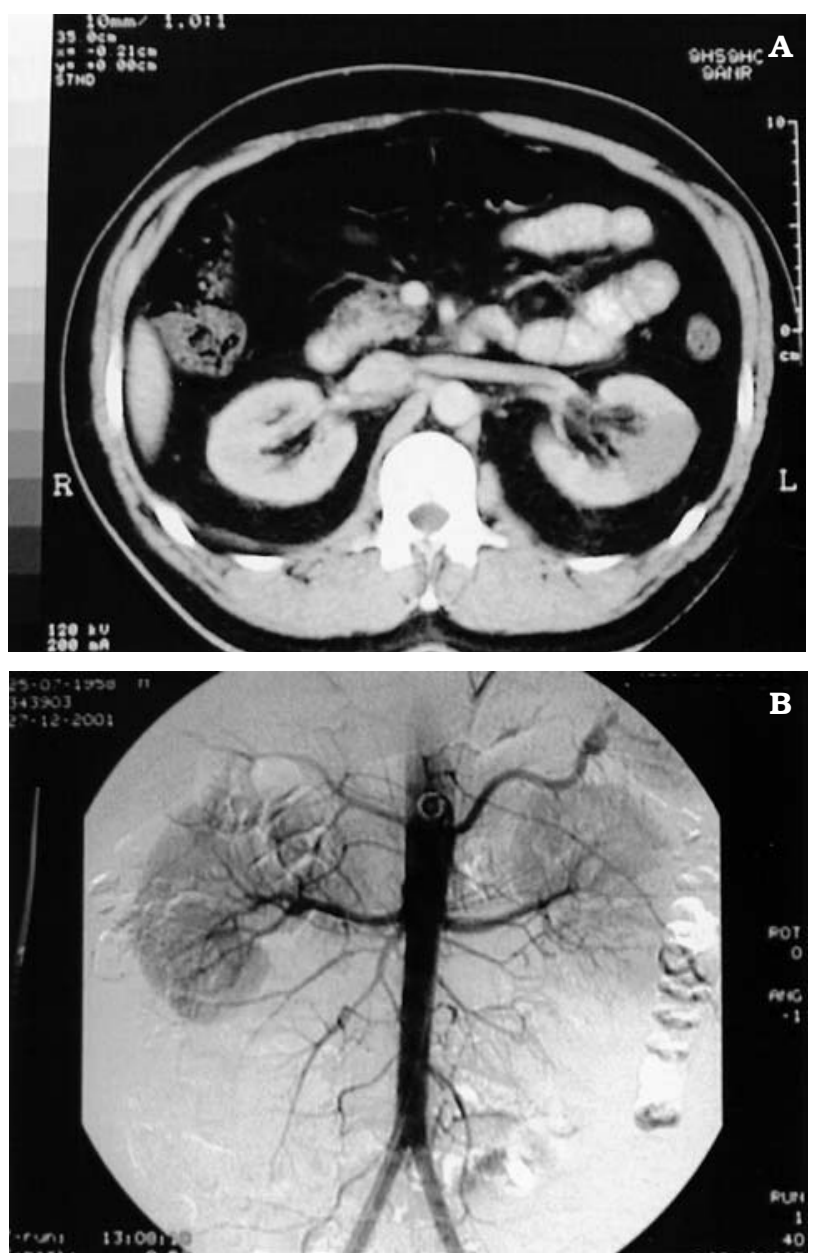

FIGURA 2 : Caso 2 - Estudios de imagen

A) TAC: área de ausencia de captación de contraste.

B) Arteriografia: áreas de déficit de perfusión multisegmentares, particularmente evidentes a nivel del polo inferior del riñón izquierdo. 
ples áreas menos prominentes que presentan déficit de perfusión igualmente. No se detectaron otras alteraciones como la presencia de macro/ microaneurismas o alteraciones de la arteria renal principal o aorta (Fig. 2B).

El estudio para descartar una enfermedad protrombótica y vascular (anticoagulante lúpico, ac. anti-cardiolipina, ANCA's, detección de crioglobulinas, ANA's, determinación de inmunoglobulinas y fracciones del complemento) resultó negativo.

Después de 15 meses de seguimiento, nos quedamos sin un diagnóstico etiológico. El enfermo se mantiene asintomático, sin nuevos episodios de embolismo o manifestaciones de enfermedad sistémica. Se ha suspendido la anti-coagulación. Mantiene una hipertensión controlada con la misma dosis de verapamilo. El último control analítico tenía una creatinina sérica de 1,2 $\mathrm{mg} / \mathrm{dL}$, y TFG de $93 \mathrm{ml} / \mathrm{min}$. El cintilograma de seguimiento demuestra un déficit funcional de la unidad renal afectada (función diferencial 41\%).

\section{DISCUSIÓN}

Descrita inicialmente en 1856 por Traube $^{1}$, la isquemia renal aguda ha sido objeto de diversas publicaciones desde principios del siglo pasado, sobre todo en forma de casos aislados, considerados como una curiosidad clínica y científica. Aunque calificada como de extrema rareza, autores como Hoxie y Coggin describen una serie de 205 casos, identificada entre 14.411 autopsias seriadas, correspondiente a una incidencia del $1,4 \%^{2}$, lo que hace pensar que es realmente un evento más habitual, aunque, tal y como apuntan los autores (sólo en dos de los casos, se realizó el diagnóstico clínico), frecuentemente no reconocido.

La etiología más frecuente del infarto renal es la embolia renal. Se estima que aproximadamente entre un 2 y un $5 \%$ de los casos de embolización periférica el árbol vascular renal está afectado, de forma aislada o concomitantemente ${ }^{16}$. Como consecuencia de la irrigación terminal de las unidades renales, la oclusión de la arteria principal o de sus ramas origina un infarto renal, total o segmentar, con necrosis y daño irreversible, en un parénquima con tolerancia baja a la isquemia. El fenómeno oclusivo embólico aún puede verse amplificado por la trombosis secundaria al espasmo provocado por el impacto del émbolo en el endotélio vascular.

En todas las series presentadas en la literatura se ha encontrado un predominio de eventos localizado a la izquierda ${ }^{2-4}$, debido según se cree al hecho de que el ángulo de implantación de la arteria renal izquierda es más favorable que el derecho. Los dos casos aquí presentados ocurrieron igualmente a la izquierda.

La fuente embólica potencial, aunque diversificada, tiene en la mayoría de los casos un origen cardiaco (Tabla 1) particularmente la fibrilación auricular secundaria a valvulopatías (presente en más de $50 \%$ de las series disponibles) ${ }^{3-6}$, seguida del infarto de miocardio. Causas más raras son la existencia de enfermedad arterial en forma de aneurisma de aorta o de la arteria renal. Se describen igualmente enfermedades autoimunes como la poliarteritis nodosa, lupus eritematoso sistémico, enfermedad de Behçet o diversos tipos de vasculitis y situaciones de síndrome antifosfolipídico, aunque en estos casos es discutible el mecanismo de la isquemia (trombosis vascular/ embolia). Es importante referir la iatrogenia. Hay casos descritos relacionados con un amplio tipo de procedimientos: angiográficos ${ }^{7}$, diagnósticos o con actuaciones terapéuticas asociadas (embolizaciones selectivas ${ }^{8}$, colocación de "stents" con

Tabla I

Fuentes potenciales origen de émbolos

\begin{tabular}{lll}
\hline & Valvulopatias & \multicolumn{1}{c}{$\begin{array}{l}\text { Estenosis mitral } \\
\text { Endocarditis bacteriana }\end{array}$} \\
\cline { 2 - 3 } Cardiaca & Arritmias & \multicolumn{1}{c}{$\begin{array}{l}\text { Fibrilación auricular } \\
\text { Flutter auricular }\end{array}$} \\
\cline { 2 - 3 } & Infarto agudo de miocardio \\
& Miocardiopatia dilatada \\
& Aneurisma ventricular \\
& Mixoma auricular \\
& Insuficiencia cardiaca severa \\
\hline \multirow{2}{*}{ Arterial } & Espontánea & Aneurisma - trombo mural \\
\cline { 2 - 3 } & Yatrogénica & Enfermedad ateromatosa \\
\hline Venosa & Embolia paradójica - defectos septales \\
\hline Otras & Embolia aguda, tumoral, émbolos sépticos, etc. \\
\hline
\end{tabular}


migración de estos materiales). La cirugía valvular cardíaca y la cirugía para el tratamiento de las lesiones aneurismáticas han estado igualmente implicadas en incidentes embólicos con afectación del árbol vascular renal. La iatrogenia debe constituir una causa emergente en un momento en que la medicina es cada día más intervencionista. En otros casos, a pesar del esfuerzo diagnóstico desarrollado, no ha sido posible determinar la causa de los mismos ${ }^{9,10}$.

Las manifestaciones clínicas varian y frecuentemente conducen a errores diagnósticos. En todas las series de revisión, retrospectivas, sólo se pudo identificar inicialmente esta condición en un porcentaje pequeño de enfermos. Autores como Lessman refieren un diagnóstico inicial correcto en menos del $25 \%$ de los casos $^{5}$. Los diagnósticos iniciales abarcan gran número de patologias como urolitiasis, pielonefritis aguda, infarto de miocardio, colecistitis aguda o situaciones de abdomen agudo. Eso mismo pasó en los casos presentados, ambos interpretados como correspondientes a procesos pélvicos inflamatorios/infecciosos.

El cuadro clínico más habitual se caracteriza por lumbalgia súbita, intensa, persistente, muchas veces resistente a los analgésicos. Puede presentar localizaciones atípicas y situarse en abdomen superior, fosas ilíacas, tórax o estar ausente $^{5}$. Frecuentemente se asocia a sintomas vegetativos como náuseas, vómitos alimentarios y diaforesis. También puede asociarse a temperaturas subfebriles. La hematuria macroscópica es de nuevo inconstante así como la hipertensión arterial. En algunas situaciones de riñón único funcionante, la única queja presentada puede ser un débito urinario bajo.

Por lo expuesto resulta claro que es necesario un alto grado de sospecha clínica para un diagnóstico precoz. El elemento más importante, en lo que se refiere a la historia clínica, va a ser la existencia de factores predisponentes. Según autores como Gasparini ${ }^{6}$ o Domanovits ${ }^{4}$, la existencia de cardiopatía, particularmente fibrilación auricular $\mathrm{u}$ otros, está presente en aproximadamente el 90\% de los casos. En la serie de Ouriel ${ }^{3}$, la existencia de episodios embólicos previos totaliza el 69\%. Estos antecedentes, en un contexto clínico y de laboratorio apropiados deben promover una investigación por imagen inmediata si tenemos la pretensión de instituir un tratamiento precoz.

$\mathrm{El}$ examen objetivo es igualmente inespecífico. Normalmente se caracteriza por la existencia de dolor a la palpación profunda, sin señales de irritación peritoneal y contacto lumbar igualmente dolorosos. La existencia de pulso arrítmico o de soplos cardíacos dependientes de una cardiopatía constituye un apoyo diagnóstico. Puede descubrirse igualmente tanto hipertensión como hipotensión, por ejemplo en el contexto de un infarto de miocardio.

Igualmente importante es la existencia, relativamente frecuente, de afección sincrónica de otros árboles vasculares ${ }^{5}$. Debe tenerse presente y descartarse la posibilidad de embolia de los territorios cerebrales, mesentérico y extremidades ya que puede contribuir al diagnóstico y, principalmente, determinar prioridades de tratamiento. Sin embargo, en los casos presentados, no había evidencia de cualquier fenómeno de este tipo. La ausencia de déficit de perfusión en el examen de las extremidades y la ausencia de hallazgos neurológicos anómalos se verificó en ambos casos.

En lo que se refiere a los hallazgos analíticos, podemos encontrar leucocitosis con neutrofilia a veces acentuada. La elevación de la láctico-deshidrogenasa (LDH), un marcador característico de necrosis celular, constituye la alteración analítica más sensible. El infarto renal produce la elevación de ambas isoenzimas LDH 1 y 2 . Gault y Steiner ${ }^{11}$ y posteriormente Winzelberg et $\mathrm{al}^{12}$, describen elevaciones de $\mathrm{LDH}$ a veces superiores a $2.000 \mathrm{UI} / \mathrm{dL}$ ocurriendo en las primeras 24 horas y persistiendo por un periodo de tiempo superior a 10 días. En los dos casos presentados, constatamos marcadas elevaciones de esta enzima (2.100 y $1.890 \mathrm{UI} / \mathrm{L})$, lo que está en acuerdo con la literatura, ya que está presente en prácticamente el $100 \%$ de los casos referenciados ${ }^{31}$, constituyendo un elemento fuertemente sugestivo del diagnóstico, encuadrada en el contexto clínico apropiado. Sin embargo, no existe gran conocimiento acerca del perfil temporal de esta elevación. A pesar de la alta sensibilidad, este hallazgo es inespecífico, puesto que en otras situaciones como el infarto de miocardio, ciertas neoplasias, isquemia mesentérica y cuadros de hemólisis 
cursan muchas veces con elevaciones importantes de esta enzima. Igualmente podemos encontrar elevaciones de las transaminasas o más raramente de la fosfatasa alcalina.

Con respecto a la orina, los datos existentes son inconstantes. La existencia de proteinuria parece ser un hallazgo bastante común (presente en más de $70 \%$ de los casos) ${ }^{13}$. La hematuria microscópica y la piuria se encuentran menos frecuentemente.

Debe realizarse un electrocardiograma por rutina, para descarte/identificación de situaciones de fibrilación auricular o infarto agudo de miocardio.

Tradicionalmente, la evaluación de estos enfermos empezaba con la realización de una urografia intravenosa. Se describen aspectos como la ausencia de eliminación de contraste del lado afectado, con ausencia completa de nefrograma, incluso en películas tardías; esto en situaciones de afectación de la rama principal de la arteria renal. La ausencia de opacificación focal del sistema colector, defecto focal del nefrograma, la mala distensibilidad de una porción del sistema colector son aspectos descritos como posibilidades de encontrarse en situaciones de infarto segmentar ${ }^{5,6,13}$.

La ecografia, método de acceso fácil, además de descartar la existencia de ectasia del excretor alto, nos proporciona datos adicionales: la existencia de un riñón de dimensiones normales, marcador del carácter agudo del fenómeno.

El TAC se considera actualmente como el método diagnóstico no invasivo de referencia ${ }^{4,13}$. $\mathrm{El}$ aspecto clásico ("cortical rim sign") designa un área subcapsular con atenuación alta envolviendo un área de atenuación baja (ausencia de captación de contraste) en la fase nefrográfi$\mathrm{ca}^{14,15}$. Estos hallazgos están igualmente presentes en situaciones de infartos segmentares/focales. La existencia de una hoja subcapsular de parénquima captando contraste deriva aparentemente de la imbibición a partir de las estructuras vecinas y sobre todo de la circulación colateral, capsular y extracapsular. Nos demuestra igualmente la inexistencia de uropatía obstructiva y alteraciones de la morfología renal. En nuestra serie permitió lograr el diagnóstico de forma eficaz.
El cintilograma renal permite demostrar alteraciones de captación del radio fármaco, con ausencia de fase vascular y de tránsito parenquimatoso aunque no nos proporcione información de carácter anatómico.

La arteriografía selectiva es considerada como la prueba reina y es claramente superior a la tomografía computarizada para la evaluación y rastreo de la vascularización renal, aunque es un método invasivo. Define la anatomía vascular y del émbolo, el grado de perfusión distal, la presencia/ausencia de circulación colateral y la existencia de enfermedad ateromatosa. Adicionalmente, puede ser seguida por medidas terapéuticas como la trombolisis selectiva. El aspecto más polémico y con menos certeza es el tratamiento. Este busca varios objetivos: alcanzar la reperfusión del órgano afectado con un mínimo de morbilidad y mortalidad, efectuar la prevención de nuevos episodios embólicos, minimizar las secuelas como la insuficiencia renal e HTA.

En los últimos 30 años, las recomendaciones terapéuticas y las opciones disponibles han sufrido cambios dramáticos, particularmente después de la aparición de las técnicas vasculares de acceso percutáneo y de los agentes fibrinolíticos. En los años 60 algunos relatos aislados demostraron retorno de la función renal después de la embolectomía quirúrgica. Después vino una época en que se recomendaba la intervención quirúrgica precoz como forma de tratamiento. Posteriormente, aparecieron informes de recuperación de unidades renales con sólo la institución de una anticoagulación. En 1973, Moyer et al. analizan los resultados comparativos entre estos dos abordajes y encuentran que la cirugía producía una mortalidad muy superior (18\% contra 0\%) y además estaba asociada a porcentajes más altos de pérdida del órgano (56 contra $23 \%)^{17}$. A partir de estos datos se recomendó la cirugía de reperfusion en situaciones de embolia bilateral o en riñón único funcionante, situaciones en que las actitudes conservadoras están asociadas a tasas de mortalidad muy alta. La aparición de los agentes fibrinolíticos proporcionó un abordaje completamente nuevo, administrados por infusión intravenosa sistémica o por administración intra-arterial, directamente sobre el émbolo. 
A pesar de la existencia de varios trabajos comparativos entre las diversas opciones disponibles (Tabla 2), los resultados no son suficientemente esclarecedores. Series extremadamente pequeñas, que abarcan amplios periodos de tiempo, enfermos de diferentes procedencias, periodos dispares de isquemia y disparidad en los procedimientos hacen casi imposible las comparaciones.

La embolectomía quirúrgica como técnica de primera opción hoy día está desfasada, aunque autores como Lacombe ${ }^{18}$ han encontrado una mayor preservación de la función renal con esta técnica, particularmente en enfermos con embolia bilateral o en riñón único funcionante, que con fibrinólisis sistémica. Sin embargo, existen múltiples trabajos que no corroboran estos resultados y presentan porcentajes de recuperación de la función de los riñones afectados entre el 12 y $30 \%$. Además, se ha asociado a complicaciones importantes, una vez que este grupo de enfermos presenta un riesgo quirúrgico elevado. Diversos autores presentan altas tasas de mortalidad quirúrgica, entre 11 y $25 \%{ }^{19,20}$, aunque se trate de series antiguas y muchos de los casos quirúrgicos se reportaren como enfermos con enfermedad embólica bilateral. Si por otro lado pensamos que con tratamiento conservador estos índices se reducen virtualmente a cero y los porcentajes de éxito son como mínimo idénticos, podemos decir

Tabla 2

Opciones terapéuticas

Embolectomia por arteriotomía

Quirúrgica

By-pass aorto-renal, ilio-renal, espleno-renal

\section{Anticoagulación}

sistémica

\begin{tabular}{ll}
\hline Fibrinolisis & Sistémica \\
& Intraarterial \\
\hline Técnicas alternativas & $\begin{array}{l}\text { Espolectomía percutánea } \\
\text { transfemoral } \\
\text { transcatén percuter (émbolos distales) }\end{array}$ \\
& $\begin{array}{l}\text { Angioplastia transluminal } \\
\text { percutánea (estenosis asociada) }\end{array}$ \\
\hline
\end{tabular}

que actualmente la cirugia se presenta como tratamiento de $2^{\mathrm{a}}$ línea, destinada a situaciones que no responden a tratamientos menos agresivos, o a las situaciones referidas de émbolo bilateral, o en riñón único en el que la cirugía es probablemente el método más rápido de garantizar la reperfusión.

La anticoagulación sistémica, por sí misma, también encuentra soporte en la literatura con casos descritos de éxito y recuperación de la función $^{5,6}$. Actúa permitiendo que los mecanismos de fibrinólisis fisiológica lleven a cabo su función y previene que se establezca la trombosis secundaria a la estasis sanguínea. Aunque exenta de mortalidad asociada, el porcentaje de éxito no supera el $30 \%$, razón por la cual actualmente su uso como tratamiento aislado está restringido para garantizar la reperfusión. Sin embargo, es un componente importante de cualquier tratamiento a nivel profiláctico, en el sentido de evitar nuevos episodios. Por esta razón, siempre debe asociarse a las diversas opciones del tratamiento. Su uso aislado todavía está indicado, como en el caso 2, cuando se considera que el pronóstico de recuperación funcional es francamente malo.

El empleo de agentes fibrinolíticos fué un paso importante en el tratamiento de esta patología. La fibrinolisis fisiológica, componente importante del proceso hemostático, empieza con la liberación del tPA ("tissue plasminogen activator") o pro-uroquinasa de las células endoteliales. Estos agentes actúan preferentemente sobre el plasminógeno adsorbido en los coágulos de fibrina y promueven su conversión a plasmina. Por su parte, la plasmina actúa sobre la fibrina, degradándola y disolviendo el trombo/émbolo.

La estreptoquinasa y la uroquinasa fueron los primeros agentes utilizados. Inicialmente empleados mediante administración sistémica por vía periférica, a semejanza de lo que se hizo para el tratamiento de otros procesos oclusivos arteriales, los resultados no fueron alentadores. Además, las complicaciones hemorrágicas alcanzaron cifras elevadas.

En la Tabla 3 se presentan los agentes actualmente disponibles y sus características. Algunos de ellos como él rt-PA son más específicos y activan de forma preferencial la plasmina en presencia de fibrina, asociándose en menor grado a 
Tabla 3

Características de los agentes fibrinolíticos disponibles

\begin{tabular}{lccc}
\hline Fármaco & Origen & Especificidad & para Fibrina \\
Estreptoquinasa & Streptococo ? hemolítico & - & Reacciones alérgicas/ Hemorragia \\
Uroquinasa & Células tubulares renales & + & Hemorragia \\
Pro-uroquinasa & Cultivo células melanoma & + & Hemorragia \\
rt PA & Recombinante & + & Hemorragia \\
APSAC & Síntesis química & $+/-$ & Reacciones alérgicas/ Hemorragia \\
\hline
\end{tabular}

fibrinolisis sistémica. En cualquier caso, siempre se recomienda respetar las contraindicaciones (Tabla 4).

En 1974 Dotter $^{21}$ describe el uso selectivo de estreptoquinasa intra-arterial, encontrando una mayor seguridad, con menor riesgo de complicaciones hemorrágicas. Fischer ${ }^{22}$ fue el primero que usó esta técnica en situaciones de embolismo de

Tabla 4

Perfil de contraindicaciones del uso de fibrinolíticos

Contraindicaciones del uso de fibrinoliticos por via sistémica

Hemorragia activa

Antecedentes de AVC hemorrágico

Antecedentes de AVC isquémico hace menos de un año

Absolutas Presencia de alteraciones vasculares intra-craneales (tumores cerebrales, malformaciones AV)

HTA severa (TA sistólica >180 mm Hg; TA diastólica $>110 \mathrm{~mm} \mathrm{Hg}$ )

Sospecha de disección de la aorta

Edad superior a 70 años

Uso de anticoagulantes (INR > 2 o 3 )

Diátesis hemorrágica conocida (Alt. de la hemostasis, Insuf. hepática, Uremia avanzada) Cirurgia major o biopsias profundas al menos de 2 a 3 semanas

Relativas Grandes heridas abrasivas o fracturas óseas Embarazo

Enfermedad ulcerosa-péptica

Enfermedad hemorrágica u oftalmológica

HTA severa controlada

Infusión estreptoquinasa hace $>5$ días $\mathrm{y}$ $<2$ años la arteria renal. Esquemáticamente, el método consiste en dejar alojada la punta del catéter de angiografia dentro del émbolo, después de la arteriografía diagnóstica y proceder a la infusión continua del agente fibrinolítico (estreptoquinasa, uroquinasa, rt-PA, etc). El tratamiento se lleva a cabo por un periodo de tiempo que oscila entre unas horas y días y va siendo monitorizado por imágenes. El catéter va siendo recolocado conforme progresa la lisis del trombo. El ritmo de la infusión de los distintos agentes no está universalmente consensuado y varía entre 3.000 y 12.000 unidades por hora, para la estreptoquinasa, y entre 5.000 y $75.000 \mathrm{U} / \mathrm{h}$ para la uroquina$\mathrm{sa}^{6,19}$, no existiendo consenso respecto a la necesidad de administración de una dosis de carga. El ritmo de administración debe ser dictado por los parámetros de hemostasis del enfermo, que deben ser monitorizados de una manera estrecha, particularmente en las primeras horas, hasta que estabilicen. El tiempo de trombina debe localizarse entre 2 y 5 veces el valor de referencia y los niveles de fibrinogéno por encima de $100 \mathrm{mg} / \mathrm{dl}$. Lo contrario puede originar pérdidas hemáticas masivas. La anti-coagulación sistémica debe iniciarse después de la lisis del émbolo con objeto de evitar trombosis " in situ" pericatéter y prevenir nuevos episodios de embolismo.

El método exhibe unos altos porcentajes de éxito. Salam ${ }^{23}$, en una serie de 10 enfermos con embolia/trombosis con afectación de la arteria renal, con evoluciones entre algunas horas y 5 semanas, presenta un porcentaje de reperfusión estimado por arteriografias subsecuentes del $70 \%$, aunque esto se hubiera traducido en un porcentaje menor de recuperación de la función de los riñones afectados. Otros presentan resultados superiores, con tasas de éxito que se acercan al 100\% ${ }^{6}$. 
Sin embargo, el método presenta algunos inconvenientes, como la necesidad de participación de un radiólogo intervencionista con experiencia en el campo de angiografía y el tiempo de tratamiento necesario (muchas veces superior a 24 horas), con las consecuencias obvias de retraso en el tratamiento eficaz en caso de fracaso. A pesar de todo, hoy está considerada como la técnica de elección cuando exista la posibilidad de realizarla en un plazo adecuado.

Otro método alternativo de tratamiento es la aspiración percutánea transcatéter. Descrito por Greenfield para situaciones de embolia pulmonar, se usó después en el tratamiento de émbolos periféricos. Encuentra aplicación en situaciones de émbolos dístales que ocurren entre el 12 y el $25 \%$ de los individuos tratados con fibrinolíticos.

Un último aspecto se refiere al pronóstico. El riñón es el objeto de irrigación de tipo terminal y presenta una tolerancia a la isquemia en condiciones normotérmicas de un periodo estimado que va de 30 a 90 minutos $^{24,25}$. De aquí la necesidad del diagnóstico/tratamiento precoz de esta situación y el hecho de que restablecer la reperfusión, en términos funcionales, no significa suceso terapéutico. Dependerá de parámetros como el periodo de isquemia (el más importante), el grado de oclusión arterial, la localización del émbolo, la presencia o ausencia de patología renal previa y la existencia de circulación colateral desarrollada.

Respecto al primero, parece obvio que cuanto mayor sea el periodo de isquemia normotérmica, menores serán las probabilidades de preservación de la unidad renal. Algunos trabajos contradicen este aspecto ${ }^{6,32}$, existiendo casos descritos con recuperación funcional después de periodos de isquemia que exceden las doce horas ${ }^{28,29} \mathrm{e}$ incluso varios días de evolución ${ }^{26,27}$. Este fenómeno solo se entiende a la luz de los trabajos de Morris, Heider y Moyer ${ }^{30}$ sobre la importancia de la presión arterial de subfiltracion en el desarrollo de la lesión isquémica renal irreversible. Normalmente, la circulación colateral para el parénquima renal a través de vasos peripiélicos, periuretéricos, pericapsulares y adrenales presenta una importancia prácticamente nula en términos funcionales. La existencia de circulación colateral desarrollada podría garantizar pre- siones de perfusión inferiores al umbral necesario para garantizar la filtración glomerular, pero superiores a los $15 \mathrm{~mm} \mathrm{Hg}$ necesarios para el mantenimiento de la viabilidad del parénquima renal o porciones del mismo. Esta circulación colateral estará más desarrollada en casos de enfermedad de la arteria renal en que estos fenómenos se amplificarán. Muchos de los casos de recuperación funcional descritos después de periodos de isquemia muy extensos, están relacionados con situaciones de isquemia renal relativa garantizando la formación de vascularización colateral importante.

Por todo lo dicho, en el momento presente es imposible definir el "cut-off" en lo que respecta a la dimensión del periodo isquémico, para definir opciones de tratamiento apropiadas al individuo enfermo. Globalmente aún así, es cierto que los mejores resultados se obtienen cuando el tratamiento es instituido en las primeras doce horas.

\section{CONCLUSIONES}

A diferencia de muchas otras entidades patológicas, la isquemia renal aguda no presenta manifestaciones clínicas o de laboratorio mínimamente específicas. Para poder llegar a su diagnóstico, es necesario tener un alto grado de sospecha clínica. Pensamos que aquellos enfermos que presentan la tríada factor de riesgo de embolia, clínica compatible y LDH sérica elevada, deben ser sometidos inmediatamente a métodos de diagnóstico por imagen para poder aplicar a tiempo, alguna de las opciones terapéuticas.

\section{REFERENCIAS}

1. Traube L. Uber den Zusammenhang vo Herz and Nierenkrankheit. Berlin: A. Hirsschwald, p. 77, 1856.

2. Hoxie HJ, Coggin CB. Renal infarction. Statistical study of two hundred and five cases and detailed report of an unusual case. Arch Int Med 1940;65:587-594.

3. Ouriel K, Andrus Ch, Ricotta JJ, Deweese JA, Green RM. Acute renal artery occlusion: when is revascularization justified ?. J Vasc Surg 1987;5(2):348-355.

4. Domanovits H, Paulis M, Nikfardjam M, Giora M, et al. Acute renal infarction: clinical characteristics of 17 patients. Medicine 1999;78(6):386-394.

5. Lessman RK, Steven FJ, Coburn JW, Kaufman JJ. Renal arterial embolism. Clinical features and long-term follow-up of 17 cases. Ann Int Med 1978;89:477-482.

6. Gasparini M, Hofmann R, Stoller M. Renal artery embolism: clinical features and therapeutic options. J Urol 1992;147 (3):567-572. 
7. Gallucci M, Alpi G, Cassanelli A, Di Natale G, et al. Renal infarction secondary to selective arteriography. Rays 1985; 10:95-97.

8. Tegtmeyer CJ, Smith TH, Shaw A, Barwick KW, Kattwinkel J. Renal infarction: a complication of gelfoam embolization of a hemangioendothelioma of the liver. AJR Am J Roentgenol 1977;128:305-307.

9. Braun DR, Sawczuk IS, Axelrod SA. Idiopatic renal infarction. Urology 1995;45:142-145.

10. Ikeda Y, Sakemi T, Kato A, Kudo S. Renal infarction in a patient without underlying diseases. Nephron 1996;74(2): 447-448.

11. Gault MH, Steiner G. Serum and urinary enzime activity after renal infarction. Canad Med Ass J 1965;93:1101.

12. Winzelberg GG, Hull JD, Agar JW, Rose BD, Pletka PG: Elevation of serum lactate dehydrogenase levels in renal infarction. JAMA 1979;242(3):268-269.

13. Lumerman JH, Hom D, Eiley D, Smith A . Heightened suspicion and rapid evaluation with CT for early diagnosis of partial renal infarction. J. Endourol 1999;13(3):209-213.

14. Sáez P, Rubio JA, Largo J, Pajín F, Cantón T. Infarto renal como forma de presentación de una estenosis mitral. An Med Interna 2000;17(10):564-565,

15. Hann L, Pfister R.C. Renal subcapsular rim sign: new etiologies and patohogenesis. Amer J Roentgen 1982;138:51.

16. Frost L, Engholm G, Johnsen S, Møler H, Hennenberg EW, et al. Incident thromboembolism in the aorta and the renal, mesenteric, pelvic, and extremity arteries after discharge from the hospital with the diagnosis of atrial fibrillation. Arch Intern Med 2001;16:272-276.

17. Moyer JD, Rao CN, Wildrich WC, Olsson CA. Conservative management of renal artery embolus. J Urol 1973;109: 138-143.

18. Lacombe M.: Surgical versus medical management of renal arterial embolism. J Cardiovasc Surg 1977;18:281,

19. Skinner RE, Hefty T, Long TD, Rosch J, Forsyth M. Recovery of function in a solitary kidney after intra-arterial thrombolytic therapy. J Urol 1989;141:108-110.

20. Martínez JCM, Cordero JMD, Belda AE, Iribarren IM, et al. Embolia sobre la arteria renal. Arch Esp Urol 1995;48(6): 569-578.
21. Dotter CT, Rösch J, Seaman AJ : Selective clot lysis with low-dose streptokinase. Radiology 1974;111(1): 31-37.

22. Fischer CP, Konnack JW, Cho KJ, Eckhauser FE, Stanley JC: Renal artery embolism: therapy with intraarterial streptokinase infusion. J Urol 1981;125:402.

23. Salam TA, Lumsden AB, Martin LG. Local infusion of fibrinolitic agents for acute renal artery thromboembolism: report of tem cases. Ann Vasc Surg 1993;7:21-26.

24. Wickham JEA, et al. Regional renal hypothermia. BJU 1987;38:727-743.

25. Semb C. Partial resection of the kidney. Ann R Coll Surg Engl 1956;19:137-155.

26. Glück G, Croitoru M, Deleanu D, Platon P. Local thrombolytic treatment for renal arterial embolism. Eur Urol 1999;38:339-343.

27. Sullivan MJ, Cormin R, Lackner LH. Embolization of a solitary kidney. Successful embolectomy after nine days. JAMA 1972;222:82-83.

28. Marrón B, Ubeda I, Gallego J, Marañes, Portolés J, et al. Functional recovery after spontaneous renal embolization in a sole kidney. Nephrol Dial Transplant 1997; 12:24172419.

29. Pineo GF, Thorndyke WC, Steed BL. Spontaneous renal artery thrombosis: successful lysis with streptokinase. J. Urol 1987;138(5): 1223-1225.

30. Morris GC, Heider CF, Moyer JG. Protevctive effects of subfiltration arterial pressure in kidney. Surg Forum 6: 623, 1955.

31. Coroner Sanchez B, Rodrigo Guanter V, Beltrán Armada JR, et al. Infarto renal agudo. Presentación de dos casos. Actas Urol Esp 2001;25(7):510-512.

32. Lip GYH, Bramwell SP, Paterson PJ. Renal artery embolism: a rare cause of renal colic. J Royal Soc Med 1991; 84(12):748-749.

Dr. L. Xambre

Servicio de Urología. Hospital Pedro Hispano

Rua Dr. Eduardo Torres - 4464-509 Matosinhos Portugal

(Trabajo recibido el 11 mayo de 2004) 